\title{
VEGETATION STATUS IN UTTARA KANNADA DISTRICT
}

\author{
T.V. Ramachandra*
}

\section{SYNOPSIS}

Uttara Kannada is the only district in Karnataka, which has a forested area of about $80 \%$ and falls in the region of the Western Ghats. It is considered to be very resourceful in terms of abundant natural resources and constitutes an important district in Karnataka. The forest resources of the district are under pressure as a large portion of the forested area has been converted to nonforestry activities since independence owing to the increased demands from human and animal population resulting in degradation of the forest ecosystem. This has led to poor productivity and regenerative capacity which is evident in the form of barren hill tops, etc. in Coastal taluks of Uttara Kannada, entailing regular monitoring of the forest resources very essential. The classification of forest is a prerequisite for managing forest resources. Geographical Information System (GIS), allows the spatial and temporal analysis of the features of interest, and helps in solving the problem of deforestation and associated environmental and ecological problems. Spatial and temporal tools such as GIS and remotely sensed data helps the planners and decision makers in evolving the sustainable strategies for management and conservation of natural resources. Uttara Kannada district was classified on the basis of the land-use using supervised hard classifiers. The land use categories identified were urban area, water bodies, agricultural land, forest cover, and waste land. Further classification was carried out on the basis

Energy \& Wetlands Research Group, Centre for Ecological Sciences Indian Institute of Science, Bangalore 560012, India EMail: cestvr@ces.iisc.ernet.in; energy@ces.iisc.ernet.in 
of forest type. The types of forest categorized were semi-evergreen, evergreen, moist deciduous, dry deciduous, plantations and scrub, thorny and non-forested area. The identified classes were correlated with the ground data collected during field visits. The observed results were compared with the historic data and the changes in the forest cover were analysed. From the assessment made it was clear that there has been a considerable degree of forest loss in certain areas of the district. It was also observed that plantations and social forests have increased drastically over the last fifteen years, and natural forests have declined.

Keywords: Western Ghats, Evergreen forests, vegetation mapping, land use, remote sensing, GIS

\section{Introduction}

Forests constitute a key natural resource as well as a source of environmental services, and are considered valuable, because they provide a wide range of benefits to the society: products (timber, fuelwood, fodder, green manure, minor produce, medicines, etc.), ecosystem services (soil conservation, hydrological regulation, carbon sequestration, etc.) and repository of biodiversity. Hence, the vegetation studies forms a vital component of any natural resource management. An ideal forest monitoring should therefore provide information on the levels of each of these stock or benefits being produced by a forest. Development of sound forest conservation and management strategies requires an understanding of the spatial and temporal patterns in the forest condition. The present study assesses the condition of the forests of Uttara Kannada district of Karnataka State, which is a heavily forested district constituting the Western Ghats and aims at determining the temporal and spatial transformation in the forested area of Uttara Kannada. The rapidly developing techniques of remote sensing and geographical information systems (GIS) potentially play a significant role in such analysis of forest condition. With the advent of remote sensing technologies, especially the satellite imagery which enables large area coverage, the mid80s saw the first attempts to come up with comprehensive forest assessments (NRSA, 1983). The present work focuses on vegetation status in Uttara Kannada district.

\section{Western Ghats}

The Western Ghats are a range of hills extending from the southern portion of Gujarat to Kanyakumari in Tamilnadu, running almost parallel to the Arabian Sea coast. The hills vary in height from about $200-3000 \mathrm{~m}$. On the western side, the distance between the seacoast and the crest of the Ghats varies from 
$4100 \mathrm{~km}$. On the eastern side ramify into the hills which eventually merge with the Deccan tableland. The Western Ghats one among the 34 global hotspots of biodiversity lies in the western part of peninsular India is a series of hills stretching over a distance of $1,600 \mathrm{~km}$ from north to south and covering an area of about $1,60,000 \mathrm{sq} . \mathrm{km}$. It harbours very rich flora and fauna and there are records of over 4,000 species of flowering plants with $38 \%$ endemics, 330 butterflies with $11 \%$ endemics, 156 reptiles with $62 \%$ endemics, 508 birds with $4 \%$ endemics, 120 mammals with $12 \%$ endemics (Daniels, 2003), 289 fishes with $41 \%$ endemics (Sreekantha et al., 2007) and 135 amphibians with $75 \%$ endemics (Gururaja, 2004). Such biodiversity coupled with the higher endemism could be attributed in this regions to prevailing climate (higher rainfall, evapotranpiration, etc.), location (mid latitude), topographic and geological characteristics of the Western Ghats. The Western Ghats region has some of the richest forests in India. The major types of forests are the following:

- Tropical wet evergreen forests, situated along the upper slopes and protected valleys.

- Semievergreen forests situated along the lower western slopes.

- Moist deciduous forests which constitute over $50 \%$ of the forest in the Western Ghats and contain many commercially valuable species.

- Dry deciduous forests which form a small percentage of the lower foot of the eastern slopes, and

- Grassy blanks which occur along the crest of upper slopes, where the vegetation mainly consists of coarse grass.

The forests of the Western Ghats region of peninsular India have undergone significant transformations over the past century, and the nature, extent and causes of these transformations have been due to deforestation, rapid urbanisation, conversion of natural forests into agricultural lands and plantations, etc. Uttara Kannada district in the Western Ghats is known for their dense forests which cover about $80 \%$ of the area of the district (Anon, 1982). The Western Ghats forms a practically unbroken relief dominating the western coast of the Indian peninsula for almost $1600 \mathrm{~km}$. They extend from the mouth of river Tapti $\left(21^{\circ} \mathrm{N}\right.$ latitude) to the tip of South India $\left(8^{\circ} \mathrm{N}\right.$ latitude) and the Palghat gap is only gap in the chain. This apparent unity in fact masks the great heterogeneity of the environmental conditions resulting from geographical, geological, and demographic differences. Working plans prepared by the Forest Department for different regions of the Western Ghats prescribe the norms for managing the forest in each area, taking into account the quality of forests, terrain and ecology. Over 13,000 species of higher plants have been recorded from India, of which 
about $27 \%$ occur in the Western Ghats. There are 58 endemic genera mostly confined to the Western Ghats. Endemic tree genera are Erinocarpus, Meteromyrtus, Otonephelium, Poeciloneuron and Pseudoglochidion.

Geographic Information Systems (GIS) are specialized data systems that preserve location identities of the information they record (Campbell, 1996) and consists of a series of overlays for a specific geographic region. These overlays may depict raw data or may show thematic information, such as soils, landuse or geology. Although these data can be visualised as a set of superimposed images, they are infact stored in digital form, suitable for retrieval and analysis.

Data for GIS can be derived from many alternative sources. For example, topographic data can be derived from topographic maps (such as of Survey of India toposheets), which also provide information on the streams, highways and forested areas. These informations are prepared by digitization. Data can also be derived from aerial photographs or other images from airborne or spaceborne sensors. The other data available is the archived data, generated in digital form. Examples include, the data for India's Census, available in digital form at the National Informatics Centre (http://www.nic.in), topographic elevation data provided by the Survey of India, land use data provided by Land records departments (State level), and remotely sensed data gathered by IRS (Indian Remote Sensing), LANDSAT (http://glcf.umiacs.umd.edu/data), etc.

GPS technology aids as convenient, inexpensive and accurate measurement of absolute location. GPS's have greatly enhanced the usefulness of remote sensing data, especially when it is necessary to integrate image data with field data for geocorrection, geo registration and for ground truthing (collection of field data at a specific location). A GPS receiver consists of a portable receiving unit sensitive to signals transmitted by a network of earthorbiting satellites. A system of 24 satellites is positioned at an altitude of about $17,600 \mathrm{~km}$, to circle the earth at intervals of 12 hours, spaced in 6 orbital planes to provide complete coverage to the earth's surface. These satellites continuously broadcast oneway signals within the Lband region of the microwave spectrum. These signals permit GPS receivers to estimate latitude, longitude, and elevation. If a receiver can acquire data as many as 4 satellites, it is possible to estimate both vertical and horizontal positions. In point positioning mode, a single GPS unit can establish horizontal location within $20 \mathrm{~m}$ with $95 \%$ accuracy, and vertical location within $30 \mathrm{~m}$.

Remote sensing is the practice of deriving information about the earth's features using images acquired from an overhead perspective, using electromagnetic 
radiation in one or more regions of the electromagnetic spectrum, reflected or emitted from the earth's surface. Analysed remote sensing data is combined with other data for a specific application. Remote sensing data aids in natural resource management to maintain sustainable development of a region.

Akbar Sha, (1988), classified the forest Uttara Kannada district based on the density of vegetation as Partially open forest (0.2-0.4 density), Medium density forest (0.4-0.8), Closed forest (greater than 0.8). Pascal (1986) focusses on the species diversity, endemic tree species of Western Ghats, vegetation cover, characteristic species, and structure of the forest and floristic composition of the wet evergreen Forests Western Ghats. Daniels (1989) classified Uttara Kannada into 5 forest zones namely, the coastal, northern evergreen, southern evergreen, moist deciduous, and dry deciduous zones. Menon and Bawa (1997) inferred that remote sensing imageries can be used to assess the health of forest ecosystem and the extent of degradation. Fuzzy classification models and vegetation indices (i.e. NDVI) were used to estimate regeneration levels, biomass, and species composition at the pixel levels. Prasad et.al. (1998), worked on the conservation planning for the Western Ghats of Kerala using GIS techniques for location of biodiversity hot spots. Results of the study reveal an increase of $194 \mathrm{~km}^{2}$ of evergreen forests in Periyar division, and a decrease in deciduous forests in 10 out of 20 forest divisions. Also there has been a massive increase in the forest plantations from $1.62 \%$ to $47.57 \%$ in certain divisions. Udayalaksmi et.al.(1998), delineated bioclimatic zones by integrating spectrally separable broad forest types from the satellite data, climate data on rainfall, temperature and physiography. Forests of Uttara Kannada were classified based on the forest type, density, rainfall, and temperature:

\section{Study Area: Uttara Kannada District}

Uttara Kannada (North Canara) district lies between $13.9220^{\circ} \mathrm{N}$ to $15.5252^{\circ}$ $\mathrm{N}$ latitude and $74.0852^{\circ} \mathrm{E}$ to $75.0999^{\circ} \mathrm{E}$ longitude (Figure 1) and covers an area of $10,291 \mathrm{~km}^{2}$. It extends from north south to a maximum of $180 \mathrm{~km}$, and from west to east a maximum width of $110 \mathrm{~km}$. The Arabian Sea borders it on the west creating a long continuous, though narrow, coastline of $120 \mathrm{~km}$ running northsouth. Goa Belgaum, Dharwad and Shimoga Dakshina Kannada form the northern, eastern and southern boundaries respectively. Uttara Kannada district is one of the northernmost districts in Karnataka State. The district comprises of 11 Taluks namely, Supa, Haliyal, Mundgod, Yellapur, Karwar, Ankola, Sirsi, Siddapur, Honnavar, Kumta and Bhatkal. 


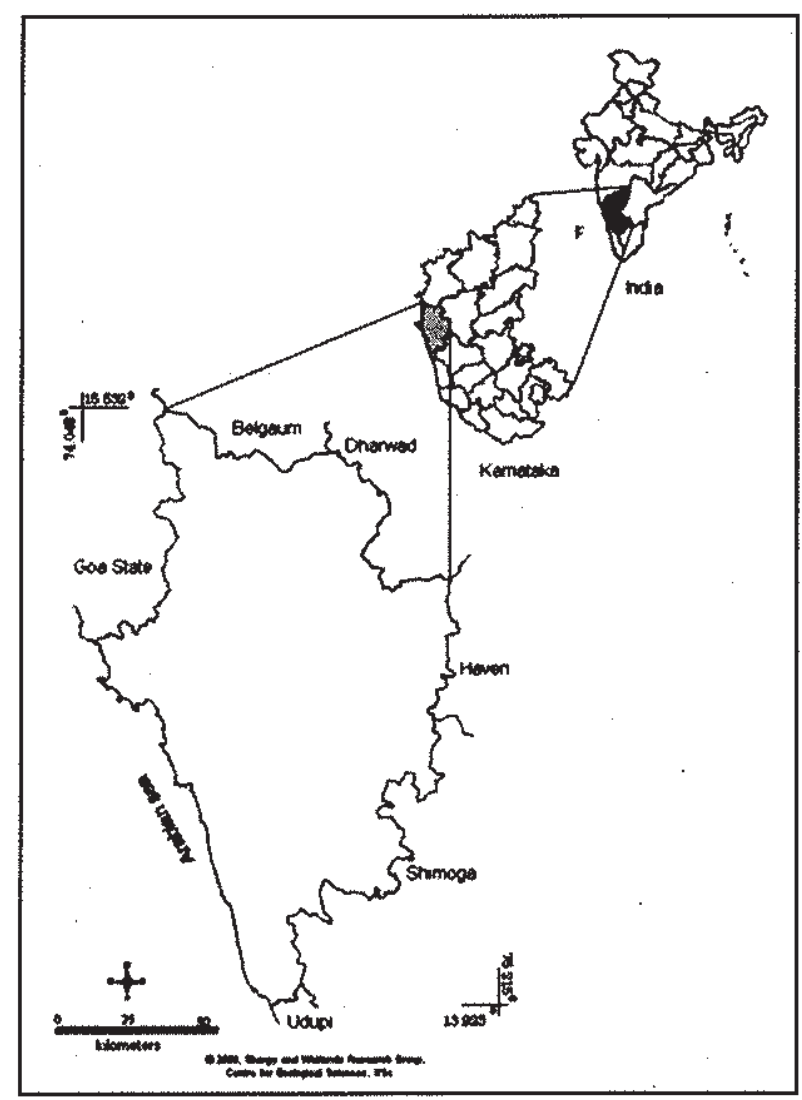

Figure 1

Geographical location of Uttara Kannada District, Karnataka State, India

Topographically, the district can be divided into 3 distinct zones namely narrow and flat coastal zone, abruptly rising ridge zone and elevated flatter eastern zone. The coastal zone is thickly populated with coconut clad villages. Ridge zone is a part of the main range of Western Ghats, which runs north to south, parallel to the coast. The flat eastern zone joins the Deccan plateau. The taluks, which comprises the narrow flat coastal zone, are: Karwar, Ankola, Kumta, Honnavar and Bhatkal.

- The taluks, which comprises the ridge zone, are: Supa, Haliyal, Yellapur, western Sirsi, and western Siddapur.

- The taluks which comprises the flatter eastern zone are: Mundgod, eastern Sirsi and eastern Siddapur. 
Table 1: Geographic area, percentage forest cover and percentage change in population

\begin{tabular}{|l|r|r|r|r|r|}
\hline \multicolumn{1}{|c|}{ Taluk } & $\begin{array}{c}\text { Area } \\
\text { Hectares }\end{array}$ & \multicolumn{1}{c|}{ Population } & \% increase & \multicolumn{2}{|c|}{ Forest } \\
\cline { 4 - 7 } Ankola & 91870 & 91310 & $1951-1991$ & \multicolumn{1}{c|}{ Area } & Area(\%) \\
Bhatkal & 35731 & 129017 & 235.00 & 25390.5 & 71.06 \\
Haliyal & 86489 & 94363 & 272.77 & 59099.8 & 68.33 \\
Honnavar & 77546 & 145842 & 125.15 & 57416.7 & 74.04 \\
Karwar & 73210 & 142845 & 177.32 & 52808.7 & 72.13 \\
Kumta & 58486 & 134144 & 155.14 & 39187.6 & 67.00 \\
Mundgod & 66890 & 77939 & 531.85 & 51167.4 & 76.49 \\
Siddapur & 85930 & 94202 & 163.86 & 62274.6 & 72.47 \\
Sirsi & 133342 & 152935 & 262.66 & 103227 & 77.41 \\
Supa & 189514 & 99519 & 453.16 & 160609 & 84.75 \\
Yellapur & 130110 & 81410 & 427.98 & 113430 & 87.18 \\
District & 1029121 & 1243526 & 212.32 & 800043.7 & 77.74 \\
\hline
\end{tabular}

The geographic area, area under forest, population density, and livestock density of each taluk of Uttara Kannada district is listed in Table 1. Supa is the largest taluk in Uttara Kannada in terms of area. It is seen that the highest populated taluk is Sirsi, whereas the percentage of population increase over a period of 40 years is maximum in Mundgod taluk. The forested area is largest in Yellapur followed by Supa taluk.

The population according to 2001 census data was 1,353,644 which amount to a population density of 132.42 persons per sq $\mathrm{km}$ implying a growth of $10.9 \%$ in population data of 1991 . Table 2 lists talukwise population density that indicates Bhatkal taluk has maximum, while Supa taluk has minimum population density. 
Table 2: Taluk wise statistics of area, population, population density, number of villages and uninhabited villages.

\begin{tabular}{|l|r|r|r|r|r|}
\hline \multicolumn{1}{|c|}{ Taluk } & $\begin{array}{c}\text { Area } \\
\text { (sq km) }\end{array}$ & $\begin{array}{c}\text { Population } \\
\text { in 2001 }\end{array}$ & $\begin{array}{r}\text { Population } \\
\text { density } \\
\text { (per sq km) }\end{array}$ & $\begin{array}{c}\text { Number of } \\
\text { villages }\end{array}$ & $\begin{array}{c}\text { Uninhabited } \\
\text { villages }\end{array}$ \\
\hline Ankola & 918.2 & 101,549 & 110.6 & 86 & 1 \\
Bhatkal & 348.9 & 149,338 & 428.02 & 61 & 0 \\
Haliyal & 847.4 & 105,851 & 124.11 & 133 & 22 \\
Honavar & 754.8 & 160,331 & 212.41 & 94 & 2 \\
Kanwar & 732.1 & 147,890 & 202.00 & 58 & 6 \\
Kumta & 582.0 & 145,826 & 250.56 & 119 & 8 \\
Mundgod & 668.1 & 90,738 & 135.81 & 94 & 6 \\
Siddapur & 859.3 & 100,870 & 117.38 & 196 & 0 \\
Sirsi & 1320.1 & 175,550 & 132.98 & 227 & 4 \\
Supa & 1890.3 & 48,914 & 25.87 & 141 & 24 \\
Yellapur & 1301.1 & 73,497 & 56.49 & 127 & 0 \\
\hline
\end{tabular}

+ without considering the population of faluk headquarters.

" population distribution maps for each taluk is given at the end.

Five major rivers of Uttara Kannada, namely, Bedthi (Bedti / Gangavalli), Aganashini (Tadri), Varda, Sharavathi and Kali, illustrated in Figure 2, form the major sources of drainage system in Uttara Kannada. These rivers flow from west through the district into the Arabian Sea. Most of the streams in the hilly tract have a long length of flow. Some of the most spectacular waterfalls of the country such as Jog Falls, Unchalli Falls, and Magod Falls are found in Uttara Kannada. The point where the rivers meet the sea, some of the finest estuaries are present.

SOILS: The soil can be described as derivatives of the most ancient metamorphic rocks in India, which are rich in iron and manganese (Pascal, 1988). The soils of the district are basically divided into two distinct zones based on topography; the coastal alluvial soil and the upghat lateritic and granitic soils. Mixed lateritic soils are found in taluks of Supa, Haliyal and Mundgod, which contains certain patches of black soil as well. The lateritic soils are highly leached, reddish brown in colour, shallow to medium in depth and loamy in texture. These soils are 


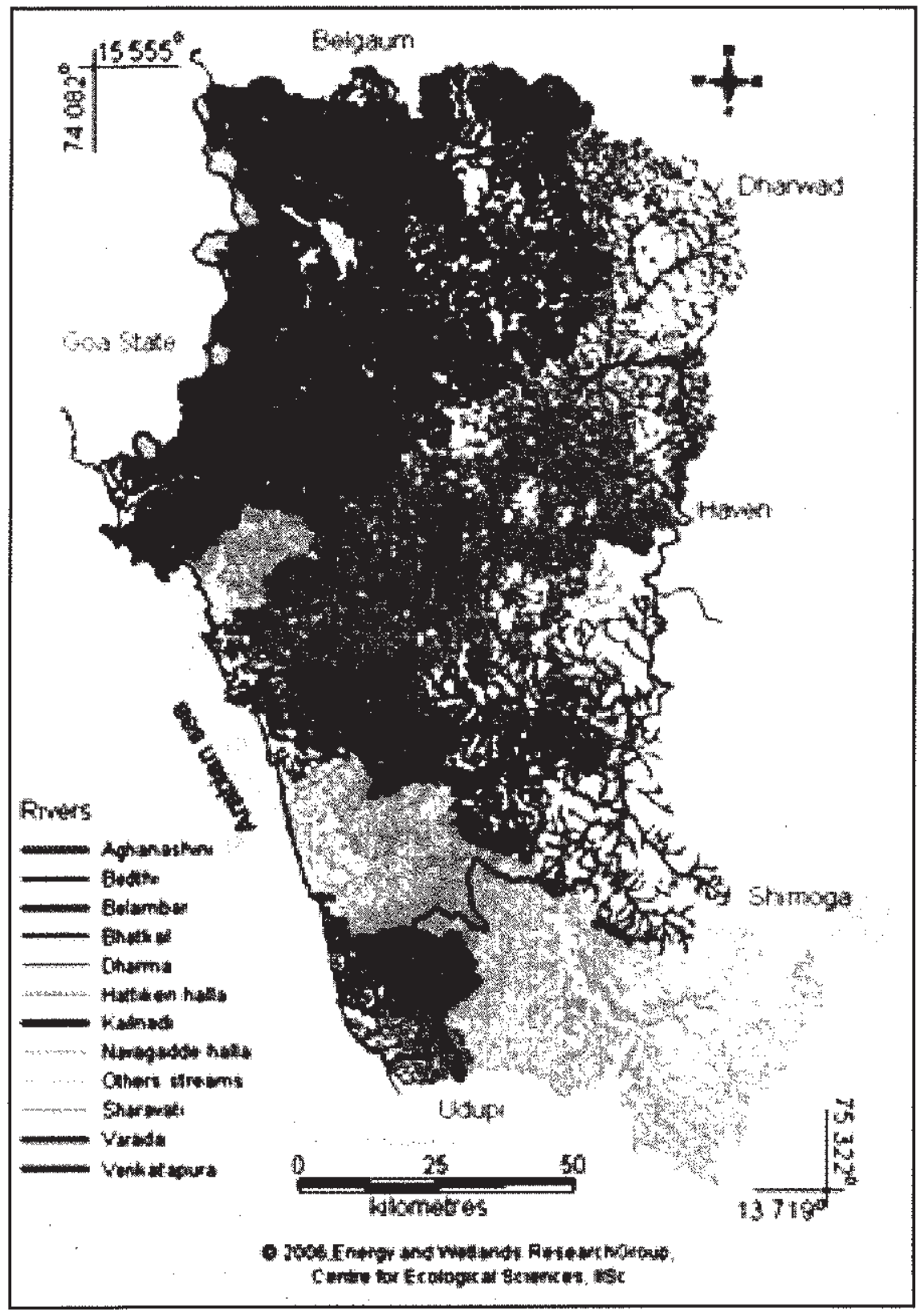

Figure 2: Rivers with Drainage Network in Uttara Kannada District 


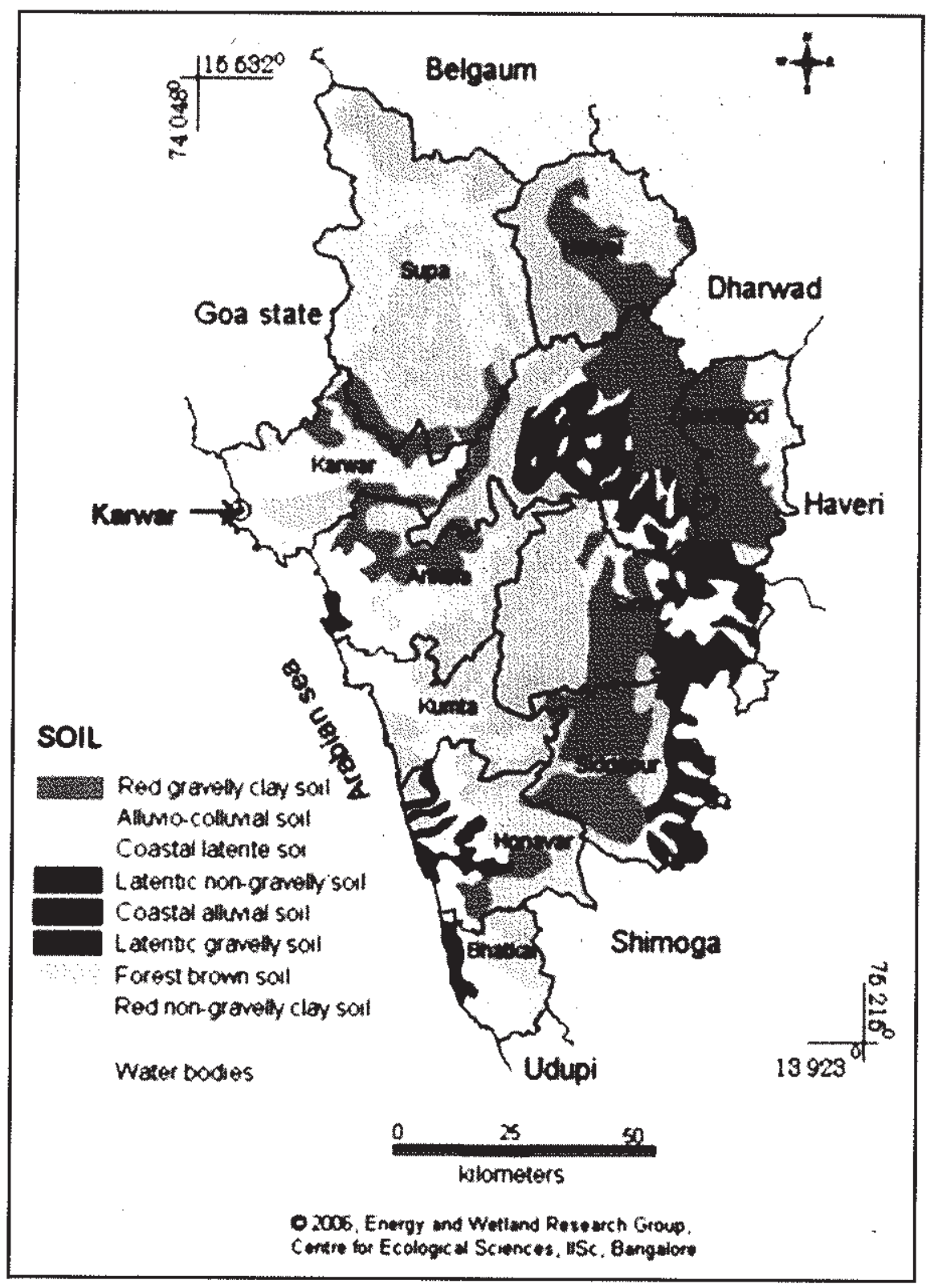

Figure 3: Soil of Uttara Kannada 
found in the taluks of Karwar, Kumta, Honnavar, Bhatkal, Sirsi and Siddapur (Figure 3).

VEGETATION: The Western Ghats of Uttara Kannada district is known for their dense forests which cover about $80 \%$ of the area of the district. The total forest of Uttara Kannada is about $8,29,151$ ha., and the per capita forest is about 0.77 ha.

The forests of Uttara Kannada can be classified into 3 categories based on density (Akbar Sha, 1988) as Partially open forest (2040\% density), Medium density forest $(4080 \%$ density) and

Closed forest (above $80 \%$ density). Based on this classification Uttara Kannada district has about $1388.89 \mathrm{~km}^{2}$ of partially open forest, $1646.16 \mathrm{~km}^{2}$ of medium density forest and $714.55 \mathrm{~km}^{2}$ of closed. forest. Depending on phenological conditions and other ecological factors, the forests of Uttara Kannada are broadly divided into two types namely Moist and Dry types. The moist type may be subdivided into evergreen, semievergreen and moist deciduous. The dry type can be divided into dry deciduous and thorny forest

The central part of Uttara Kannada is of the evergreen type as shown in Figure 4. They are composed of very tall trees, forming a very dense canopy and are many storied and impenetrable. The rainfall in this forest is as high as 4000 $5000 \mathrm{~mm}$. The semievergreen forests are seen in pockets and often merges with the evergreen and the moist deciduous type. Therefore distinguishing them is rather difficult.

In the moist deciduous forest, tree species remain deciduous only for a short time. These forests have semievergreen species in the upper canopy and evergreen in the lower storey. In these forests, some moist places have predominance of bamboo and on red soil Xylia is present. They have a rainfall of about 1000 $2000 \mathrm{~mm}$.

- Evergreen species: Dipterocarpus indicus, Diospyros candolleana, Artocarpus hirsutum, Vateria indica, Hoppea intergrifolia, Memecylon umbellatum, Mangifera indica, Actinodaphne agustifolia, Holigarna grahmie, Calamus rotang

- Semievergreen species: Cinnamomum malabaricum, Holigarna arnottiana, Dalbergia latifolia, Ficus spp., Pterocarpus marsupium, Aglaia roxbhurgiana. 


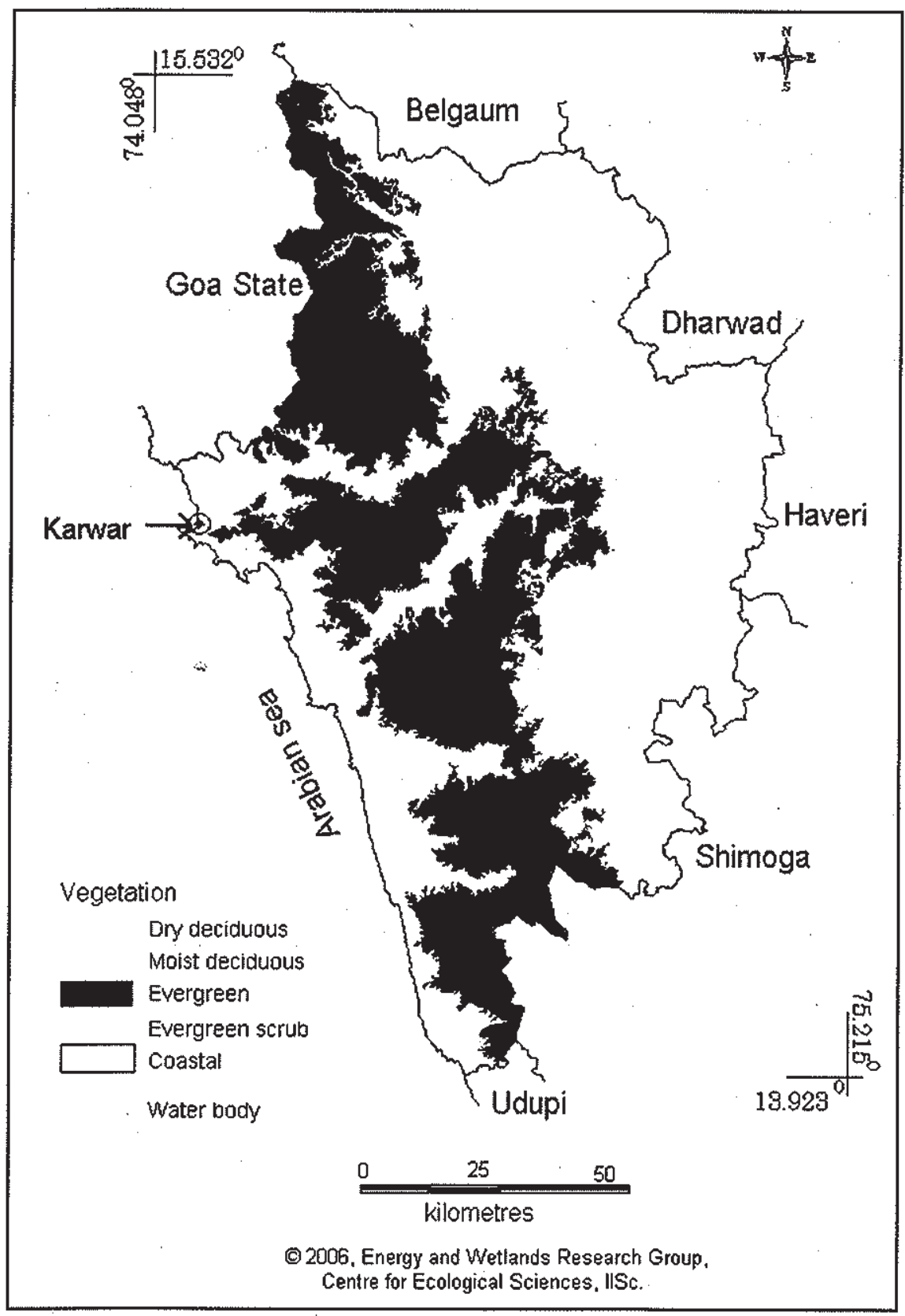

Figure 4: Vegetation distribution for Uttara Kannada District. 
- Moist deciduous species: Terminalia paniculata, Terminalia tomentosa, Xylia xylocarpa Careya arborea, Spondias spp., Tectona grandis, Lagerstrọemia parviflora, Dillenia pentagyna, Strychnos nuxvomica, Bambusa arundinaceae.

- Dry deciduous species: Acacia catechu, Sepium insigne, Anoegissus spp., Bauhinia racemosa, Bombax ceiba.

- Plantations: Tectona grandis, Areca catechu, Cocos nucifera, Casuarina equisetifolia, Acacia auriculiformis, Acacia nilotica, Eucalyptus spp.

Uttara Kannada vegetation is divided into 5 broad zones by Daniels et.al.(1989) namely, Coastal zone, Northern evergreen zone, Southern evergreen zone, Moist deciduous zone and Dry deciduous zone. Uttara Kannada has 21 habitat types according to Daniels (1989), based on a study in $181,5 \times 5 \mathrm{~km}$ grids. They are, Evergreen forests (65\%), Rocky cliffs (14\%), Degraded evergreen thickets (17\%), Moist grasslands (9\%), Moist/dry teak (29\%), Humid betelnut (50\%), Freshwater marshés $(25 \%)$, Exotic tree plantations $(25 \%)$, Rivers (10\%), Hillstreams $(55 \%)$, Coastline (9\%), Beaches (6\%), Coastal coconut (9\%), Estuaries (5\%), Scrub (2\%), Dry deciduous forest (5\%), Moist/Dry Bamboo facies (6\%), Moist/Dry cultivation (31\%), Moist/Dry Eucalyptus (10\%), Moist Deciduous forests (18\%), Urban population $>1000(22 \%)$.

The major vegetation types of Uttara Kannada have been broadly grouped as

- Natural vegetation: which includes evergreen, moist deciduous and dry deciduous forests with their degraded stages.

- Plantations or Monocultures: The plantations of Areca catechu (Betelnut), Tectona grandis (Teak), Eucalyptus sp. (Blue gum) and other exotics were among the monocultures studied.

According to Pascal's Forest Map of South India (Figure 5) the vegetation is classified as follows:

Group 1. Evergreen or semi-evergreen climax and potentially related forests

\section{Evergreen or semi-evergreen climax and potentially related forests}

- Low elevation $(0-850 \mathrm{~m}$ in the south and $0-650 \mathrm{~m}$ in the north). 


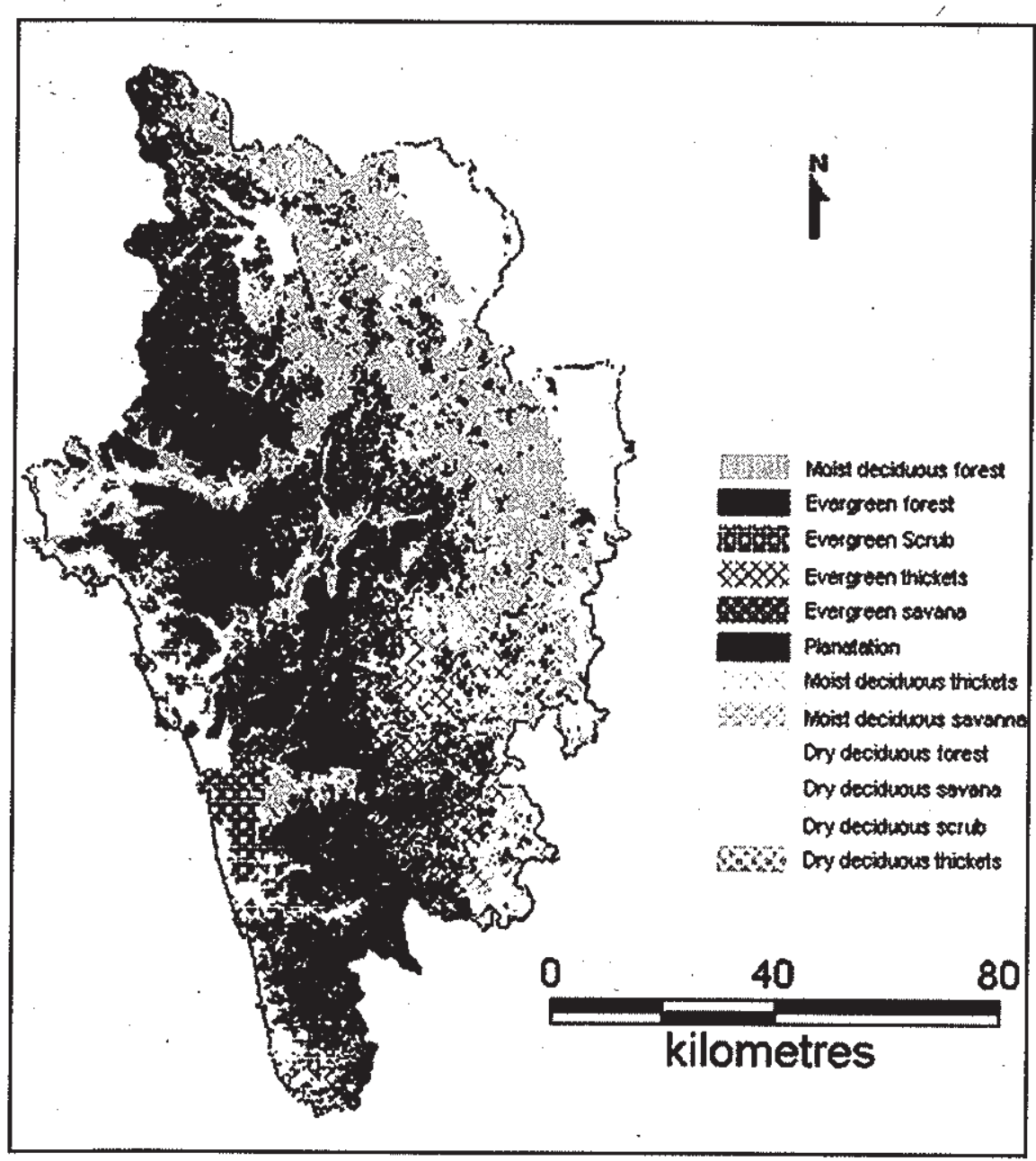

Figure 5: Vegetation distribution for Uttara Kannada District

Dipterocarpus indicus-Diospyros candolleana-Diospyros oocarpa type: Honnavar and Kumta (Scanty distribution only)

Persea macrantha-Diospyros spp-Holigarna type: Honnavar and Kumta. Acacia catechu, Casuarina equisetifolia, Eucalyptus spp., and Tectona grandis 
Diospyros spp-Dysoxylum malabaricum-Persea macrantha kan forest type: Eastern Sirsi.

- Medium elevation (650-1400 m)

Transition type: Joida

Memecylon umbellatum-Syzygium cumini-Actinodaphne angustifolia type.

\section{Secondary or degraded stages}

- Evergreen and semi-evergreen forests

Disturbed low elevation: all taluks except Haliyal and Mundgod

Disturbed transition: Joida.

Secondary low elevation: Bhatkal, Honnavar, Kumta, Sirsi and Siddapur.

- Secondary moist deciduous forests

Dense forest: Joida, Yellapur, and Sirsi.

Woodland to Savanna woodland: all except Haliyal and Mundgod.

- Other degraded stages

Thicket low elevation: all except Haliyal and Mundgod.

Thicket medium elevation: Joida.

Tree savanna to grass savanna low elevation: all except Haliyal and Mundgod.

Scattered shrubs low elevation: Bhatkal, Honnavar, Kumta, Ankola, and Karwar.

\section{Group II. Deciduous climax forests and degradation}

These forests and their degradations occur in the north-eastern parts of the district. 


\section{- Plantations}

Acacia catechu, Casuarina equisetifolia, Eucalyptus spp., and Tectona grandis are planted widely in the district.

\section{Objectives}

The main objective of this study is to assess the spatial and temporal vegetation changes and land-use pattern in the study area using GIS, GPS and remote sensing data. Also to classify the vegetation cover in the study area based on the forest types such as: Evergreen forest, Semi-evergreen forest, Moist deciduous forest, Dry deciduous forest and Thorny forest.

\section{Methodology}

The preliminary method adopted was to collect secondary data regarding the vegetation, forest cover, topography, species diversity, landuse in the past etc. of the study area, from governmental organizations such as forest department, forest research institutes, as well as non-governmental institutes such as French Institute, Pondicherry. Data was also obtained from reviewing certain literature works, which were of significant importance to this study. Apart from these, field investigations were undertaken in order to ascertain the spectral signatures in the remotely sensed data with ground condition type of patch, type of vegetation, etc. After collecting the essential information required for this study, the digital analysis of these data was carried out. The methodology adopted for carrying out this analysis could be categorised into 4 steps as follows:

- Digitization

- Ground truth data

- Remote sensing data

- Digital Image Processing

- Data analyses, data integration

DIGITIZATION: Survey of India (SOI) topographical maps of scale 1:50,000 and $1: 2,50,000$, covering all taluks of Uttara Kannada district depicting taluk boundaries, road and rail network, and drainage pattern (Figure 2) were digitized. The district boundary was digitized using toposheets $48 \mathrm{~J}, 48 \mathrm{I}, 48 \mathrm{M}$, and $48 \mathrm{~N}$ each of scale 1:2,50,000. The taluk boundaries, road and rail network, and the drainage network were digitized from toposheets of scale 1:50,000. The 
RMS errors for digitization were checked and found to be within the acceptable limits for the scales of maps used. The lat/long coordinate system was used for digitization. Vegetation map of South India (Figure 5) of scale 1:2,50,000 was digitized using Vegetation map developed by French Institute (1984). This helps in temporal analyses to find out the changes in vegefation during the last twenty years.

These digitized images (major road network and drainage network) were used to georegister and also to implement geo correction of the satellite imageries. Vector layer of the district boundary and taluk boundaries were converted to raster images in order to crop the satellite imageries, along the boundary of the study area.

GROUND TRUTH DATA : False Colour Composite (FCC) was generated with the band-2 (green), band-3 (red) and band-4 (near infrared) and is given in Figure 6. The vector polygons of different land use categories were extracted from the FCC and field visits using GPS were made to collect attribute information corresponding to polygons in the heterogeneous patches of the image. Both supervised and unsupervised classification approaches were tried to identify land use categories. Ground data were collected through field visits. The training

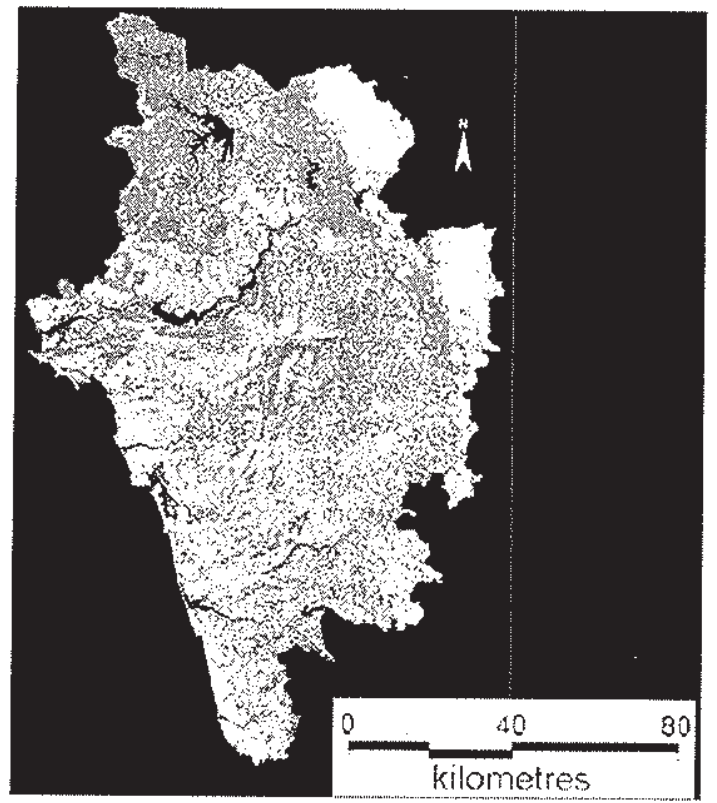

Figure 6: FCC of Uttara Kannada 
polygons were selected such that it could be easily identified and located on the satellite imagery and distributed uniformly all over the region. Based on this criterion, the control points, at crossroad junctions, bridges, forest area, agricultural lands, national highways, railway junction etc., were marked. These are referred as GCP's or Ground Control Points. The ground control points were marked using Global Positioning System (GPS) GARMIN ver 2.01, which marks the latitude and longitude of the points taken, in degrees. Also it gives the altitude of the point marked, in meters. The main aims of obtaining the ground control points, is to georegister the satellite imagery (in the image restoration process), and to use as interpretation keys for image classification.

The type of forest cover in the study area was also studied during the field visits. The type of vegetation, characteristic species of the forest type, and the forested areas were assessed. The data thus obtained was used to classify the satellite imagery based on the landcover, land use and also to sub-classify based on the forest type.

REMOTE SENSING DATA: Remote sensing data of IRS-1D; Path-97, Row-62, 63; LISS III sensor; $5^{\text {th }}$ March 1999 and 24th April 2005 satellite imageries corresponding to Uttara Kannada district were procured from National Remote Sensing Agency (NRSA), Hyderabad. While procuring these images it was ensured that, the data obtained is of latest time scale, and image scenes have cloud cover less than $5 \%$. Summer season data was procured to carry out landcover classification (level 1.classification vegetation, soil, water, etc.)

Land Cover Analysis Kolar District: The analysis of vegetation and detection of changes in vegetation pattern are keys to natural resource assessment and monitoring. Healthy green vegetation has different trends in interaction with the energy in visible and near-infrared regions of the electromagnetic spectrum. This strong contrast between the amount of reflected energy in the red and nearinfrared regions forms the basis to develop quantitative indices of vegetation condition using remotely sensed data. Various vegetation indices (VI) have been developed for qualitative and quantitative assessment of land cover. The slopebased and the distance-based vegetation indices ( $/ \mathrm{s}$ ) help in land cover analysis depending on the extent of vegetation and soil in a region. In particular, the sensors with spectral bands in the RED and NIR lend themselves well to vegetation monitoring since the difference between the red and near-infrared bands have been shown to be a strong indicator of the amount of photosynthetically active green biomass. NDVI separates green vegetation from its background soil brightness. It is expressed as the difference between the near infrared and red bands normalised by the sum of those bands, i.e. 
This is the most commonly used Vl as it retains the ability to minimize topographic effects while producing a linear measurement scale. In addition, divisions by zero errors are significantly reduced. The index normalizes the difference between the bands so that the values range between -1 and +1 . The negative value represents non-vegetated area while positive value represents vegetated area.

Land use analysis: Classification of remotely sensed data requires the assignment of each of the pixels on an image to a class. The classification approach is based on the assumption that each of the classes on the ground has a classspecific spectral response with each of the classes varying in spectral patterns. There is substantive variation in the distribution of the pixel reflectance values depending upon where the samples are drawn within a land use type. The spectral information contained in the original and transformed bands is then used to characterize each class pattern, and to discriminate between classes. Both supervised and unsupervised classification approaches were tried to identify land use categories.

Supervised Classification: In case of supervised classification, known specific types of land-use are identified based on the spectral reflectance patterns or signatures of different features information classes. These are called training sites. With theses a statistical characterization of reflectance for each individual class were done, which is known as signature analysis and it may be as simple as the mean or range of reflectance on each band, or as complex as analyses of variance and covariance over all bands. After the signature analysis is done the image is classified by examining the reflectance of each pixel and making a decision about which of the signature it resembles most and assigning the appropriate pixels to their respective class. This decision making and assigning of pixels to their respective classes is done by classifiers. The three most commonly used classifiers are:

- Parallelepiped: It characterizes each class by a range of values on each band. This range is defined by the minimum and maximum values of the training sites. It then classifies all the pixels, which fall within this range. If a pixel does not fall within this range then it is left unclassified.

- Minimum distance to mean: Based on the training site data, it characterizes each class by its mean position on each band. Suppose 3 bands are used for analysis, the reflectance value of a pixel in all the three bands is taken, and the mean value is calculated. All the pixels which have the same value are assigned to their respective classes. The unassigned pixels are then assigned to that class to which it is nearer. 


$$
\hat{k}=\frac{N \sum_{i=1}^{r} X_{i i}-\sum_{i=1}^{r}\left(X_{i+1} . X+i\right)}{N^{2}-\sum_{i=1}^{r}\left(X_{i+1} . X+i\right)}
$$

- Maximum likelihood: Using the information from a set of training sites, it uses the mean, variance and covariance data of the signatures to estimate a probability that a pixel belongs to each class.

Accuracy estimation in terms of producer's accuracy, user's accuracy, overall accuracy and Kappa coefficient were subsequently made after generating confusion matrix. The Kappa coefficient is a measure of the difference between the actual agreement between reference data and an automated classifier and the chance agreement between the reference data and the random classifier as shown in equation (1) and equation (2). This statistics serves as an indicator of the extent to which the percentage correct values of an error matrix are due to "true" agreement versus "chance" agreement. It incorporates the non-diagonal elements of the error matrix as a product of the row and column diagonal.

where $r=$ number of rows in the error matrix

$X_{i}=$ the number of observations in row $\mathrm{i}$ and column $\mathrm{i}$ (on the major diagonal)

$X_{i+}=$ total of observations in row $i$

$X+i=$ total of observations in column $i$

$N=$ total number of observations included in matrix

Of the three hard supervised classifiers, Maximum likelihood is the best and computationally difficult. The forest classes obtained were then identified as evergreen, semi-evergreen, moist deciduous, and dry deciduous. Temporal change analysis was done considering the forest cover of Uttara Kannada in 1984. Digitised Forest Map of South India generated by J.P. Pascal of the French Institute, Pondicherry (1984), was compared with the classified image obtained, by overlaying the image on the digitized map. This gave the change in the forest cover and also the forest types over a period of about fifteen years. 


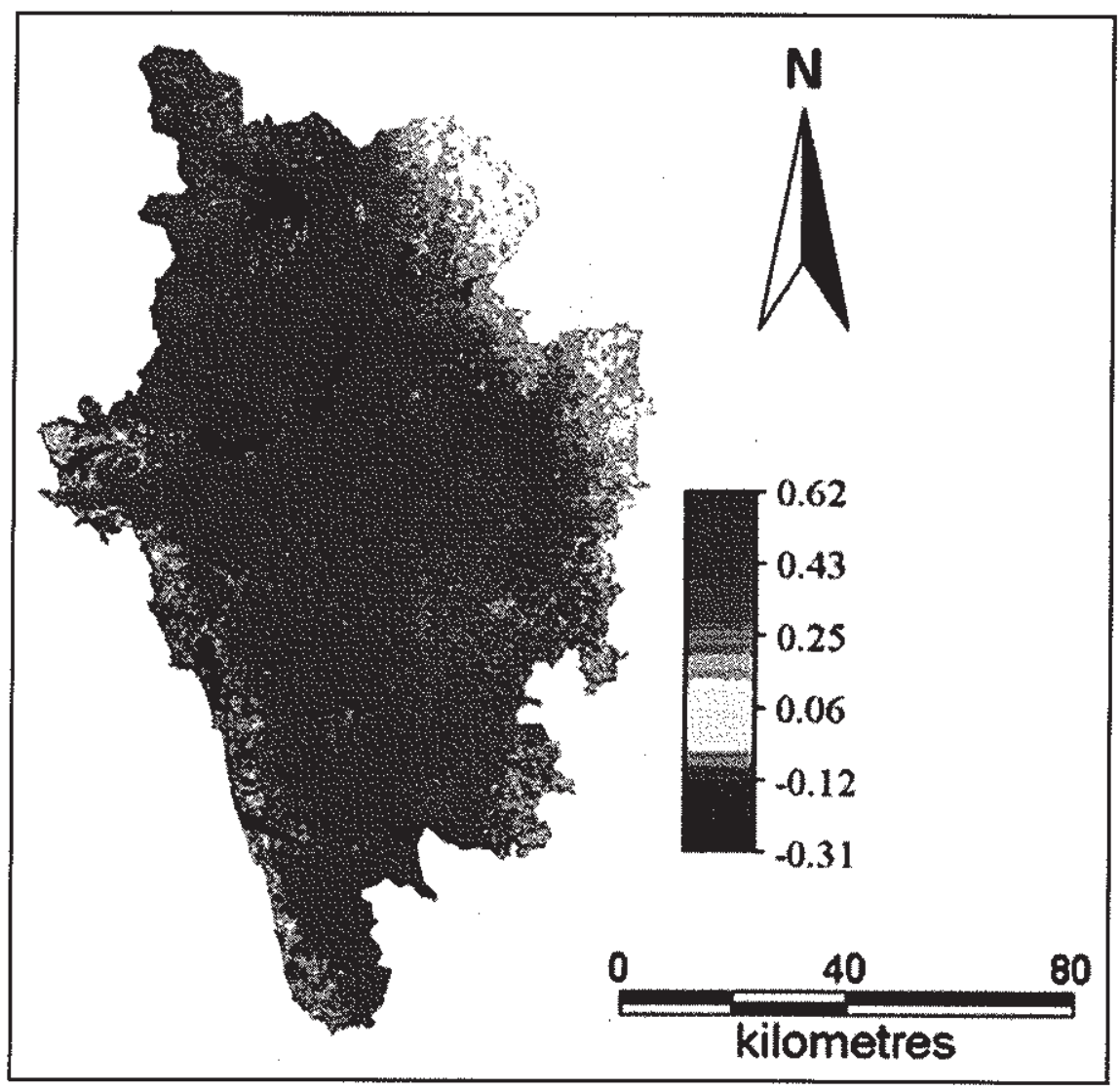

Figure 7: NDVI of Uttara Kannada

\section{Results and Discussion}

Figure 5 illustrates the forest cover in Uttara Kannada in 1984. The figure shown is a digitized vector image obtained from the Forests of South India map, by the French Institute. The figure shows a large area covered under the evergreen belt. Semi-evergreen is seen in pockets blended with the evergreen and moist deciduous patches. Moist deciduous forests are found towards the eastern part of the district. It is observed that the dry deciduous patch is very less and is found in the north eastern part of the district, mainly in Mundgod taluk. Figure 7 depicts the NDVI image of Uttara Kannada. This gives the vegetative cover of the district. The Western Ghats region of the district showed a very high vegetative index value implying that the area is heavily forested. Besides the river valley region also showed a reasonably high index value. 


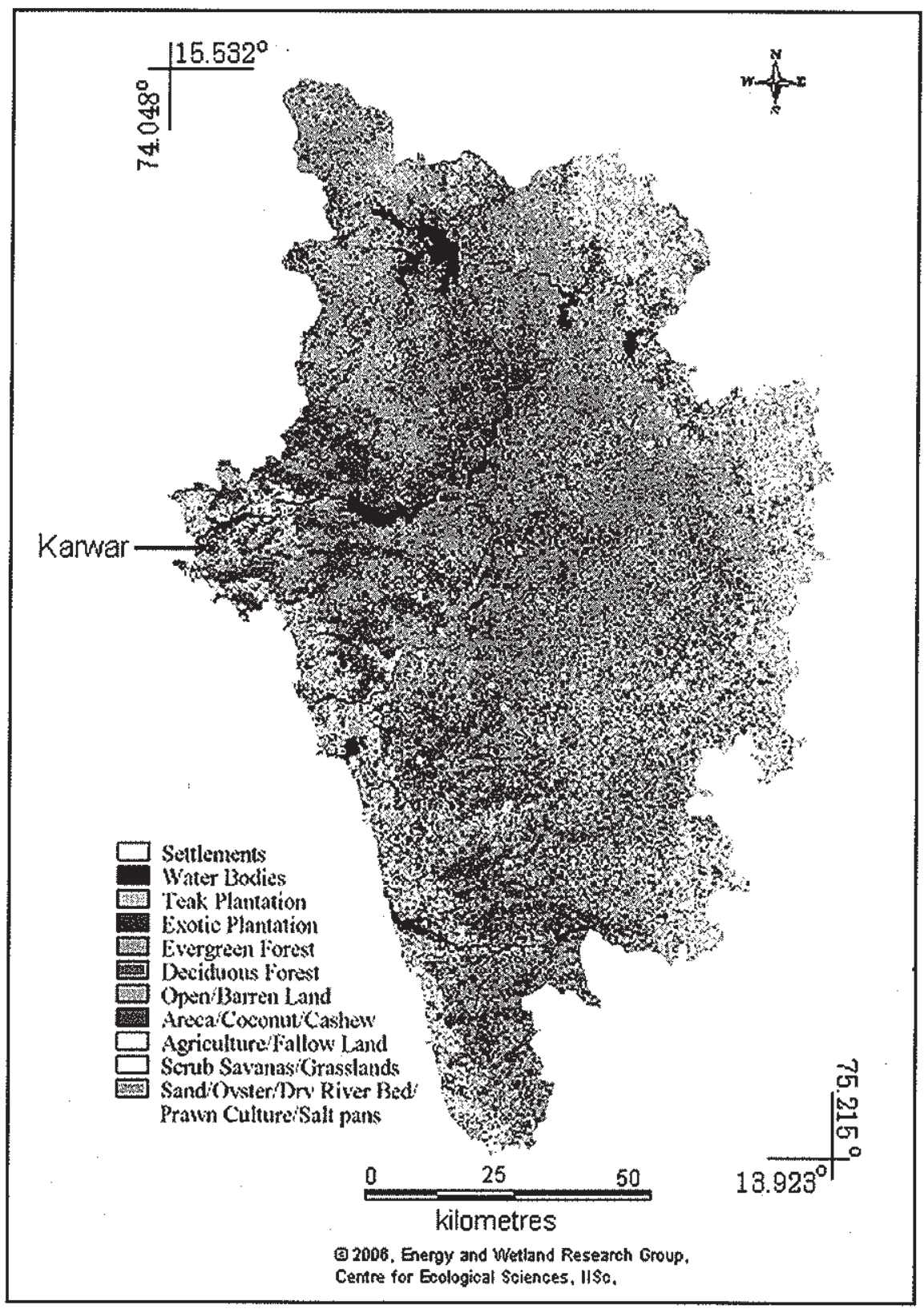

Figure 8: Land-use map from IRS ID, LISS 3 data 
Figure 6 depicts merged and cropped false colour composite (FCC) image of Uttara Kannada. This figure clearly distinguishes the different features associated with the image. The features that are at a high altitude such as the ghat section, and hilly areas could be identified easily from this image. Also the vegetation cover is very distinct, being bright in colour and thus easily identified. The transportation network such as the Konkan railway, which is a recent construction (not marked on the toposheet), is very distinctly visible on this composite image. Built up areas, water bodies, bridges, national highways and agricultural land are also clearly distinguishable.

Land-use classification for Uttara Kannada was done using parallelepiped, minimum distance to mean and maximum likelihood hard supervised classifiers respectively. The area is classified into 11 land-use classes namely, urban agricultural land, waste land, forest, water bodies, etc. Parallelepiped classified images contains many areas which are left unclassified. While in minimum distance to means classifier, many pixels were not been assigned to the appropriate class or left unassigned. Figure 8 depicts landuse map of the district classified using Gaussian Maximum Likelihood Classifier (GMLC). The level of accuracy in GMLC is $88.5 \%$ (Table 4 and 5)compared to unsupervised classifier (58.07\%). Kappa coefficient - KHAT $k$ value $(0.79)$ obtained from supervised classification matrix indicated that an observed classification is 79 percent better than one resulting from a chance.

Table 3: Area under various land-uses in Uttara Kannada district

\begin{tabular}{|l|c|c|}
\hline Land-use class & Area, Sq. km & Area in percent \\
\hline Settlements & 139.16 & 1.31 \\
\hline Water Bodies & 179.94 & 1.69 \\
\hline Teak Plantation & 1284.54 & 12.07 \\
\hline Exotic Plantation & 798.18 & 7.5 \\
\hline Evergreen Forest & 4325.28 & 40.66 \\
\hline Deciduous Forest & 842.78 & 7.92 \\
\hline Open/Barren Land & 591.63 & 5.56 \\
\hline Areca/Coconut/Cashew & 806.85 & 7.58 \\
\hline Agriculture/Fallow Land & 1023.17 & 9.62 \\
\hline Scrub Savannas/Grasslands & 580.31 & 5.45 \\
\hline $\begin{array}{l}\text { Sand/Oyster/Dry River Bed/ } \\
\text { Prawn Culture/Salt pans }\end{array}$ & 66.71 & 0.63 \\
\hline
\end{tabular}


According to Parallelepiped classifier, the percentage of each type of landcover area is less compared to that of Minimum Distance to Mean classifier and the

Table 4: Error matrix of classified data (using MLC)

\begin{tabular}{|l|r|r|r|r|r|r|r|r|r|r|r|r|}
\hline LU & AFL & EGF & DEF & SSG & SMS & WAB & EPL & ACC & TPL & OBL & SOR & Total \\
\hline AFL & 1055 & 2 & 0 & 62 & 67 & 0 & 18 & 33 & 13 & 972 & 7 & 2229 \\
\hline EGF & 1 & 3452 & 715 & 1 & 0 & 0 & 15 & 17 & 249 & 0 & 0 & 4450 \\
\hline DEF & 204 & 143 & 2320 & 8 & 0 & 0 & 316 & 446 & 83 & 6 & 0 & 3526 \\
\hline SSG & 284 & 113 & 104 & 462 & 2 & 0 & 174 & 58 & 324 & 18 & 0 & 1539 \\
\hline SMS & 247 & 0 & 0 & 20 & 262 & 0 & 7 & 10 & 7 & 809 & 4 & 1366 \\
\hline WAB & 0 & 0 & 0 & 0 & 0 & 50562 & 0 & 0 & 0 & 0 & 2 & 50564 \\
\hline EPL & 0 & 482 & 12 & 5 & 17 & 0 & 252 & 0 & 260 & 417 & 0 & 1445 \\
\hline ACC & 5 & 1466 & 3 & 0 & 0 & 0 & 194 & 1742 & 0 & 0 & 0 & 3410 \\
\hline TPL & 21 & 6 & 0 & 0 & 19 & 0 & 23 & 62 & 1237 & 0 & 0 & 1368 \\
\hline OBL & 14 & 1 & 1 & 16 & 79 & 0 & 236 & 0 & 17 & 4631 & 0 & 4995 \\
\hline SOR & 0 & 0 & 0 & 0 & 0 & 5 & 0 & 0 & 2 & 0 & 2987 & 2994 \\
\hline Total & 1831 & 5665 & 3155 & 574 & 446 & 50567 & 1235 & 2368 & 2192 & 6853 & 3000 & 77886 \\
\hline
\end{tabular}

Table 5: Producers, Users and Overall Accuracy for the error matrix

\begin{tabular}{|l|c|c|c|c|c|c|c|c|c|c|c|}
\hline LU & AFL & EGF & DEF & SSG & SMS & WAB & EPL & ACC & TPL & OBL & SOR \\
\hline $\begin{array}{l}\text { Producers } \\
\text { Accuracy }\end{array}$ & 57.6 & 60.9 & 73.5 & 80.5 & 58.7 & 100.0 & 20.4 & 73.6 & 56.4 & 67.6 & 99.6 \\
\hline $\begin{array}{l}\text { Users } \\
\text { Accuracy }\end{array}$ & 47.3 & 77.6 & 65.8 & 30.0 & 19.2 & 100.0 & 17.4 & 51.1 & 90.4 & 92.7 & 99.8 \\
\hline $\begin{array}{l}\text { Overall } \\
\text { Accuracy }\end{array}$ & & & & & & & & & & & 88.5 \\
\hline $\begin{array}{l}\text { Kappa } \\
\text { Coificient }\end{array}$ & & & & & & & & & & & \\
\hline
\end{tabular}

Agriculture/Fallow Land: AFL, Areca/Coconut/Cashew: ACC, Exotic Plantation: EPL Teak Plantation: TPL, Evergreen Forest: EGF, Deciduous Forest: DEF, Scrub Savanas/ Grasslands: SSG, Settlements: SMS, Open/Barren Land: OBL, Sand/Oyster/Dry River Bed/Prawn Culture/Salt pans: SOR, Water Bodies: WAB 
Maximum likelihood classifier. For example, the percentage of forested area (evergreen type) depicted in case of Parallelepiped is 34, whereas, in case of Minimum Distance to Mean, it is $39.59 \%$, and in case of Maximum Likelihood it is about $40.66 \%$. Area under various land-uses are listed in Table 3. The Maximum likelihood classifier is the best type of classifier with the overall accuracy (Table 4 and 5) of $88.5 \%$ compared to the other two types.

On comparing Figures 5 and 8 , it is very clear that the evergreen forests have undergone tremendous transformation. Most of the evergreen forested area have been transformed into semi-evergreen forests, and some have been converted into plantations such as, Teak, Arecanut, Acacia spp., etc. It is found that semievergreen and moist deciduous forest types predominate the forested area of Uttara Kannada. The complete stretch of the central ridge zone (ghat section), which was once dominated by the evergreen forests, is now dominated by the semi-evergreen forest. Evergreen is seen in patches mainly towards the southwest and in the ghat section. Moist deciduous is seen almost in all places distributed throughout the district. It is more common in the eastern Sirsi, south of Yellapur, eastern Siddapur and western region of the coastal taluks. Dry deciduous forests were spotted in the taluks of Mundgod, Haliyal, western Sirsi and north-eastern part of Yellapur.

\section{Acknowledgement}

I am grateful to the Ministry of Environment and Forests, Government of India and Indian Institute of Science for the financial support. I thank Ms. Shruthi, Ms. Savitha, Mr.Rosario M. Furtado and Mr. P.R. Bhat for their co-operation during field data collection.

\section{Bibliography}

- Akbar Sha A., (1988), Integrated development of forests in Western Ghats, Karnataka Forest Department.

- Campbell J., (1996), Introduction to Remote Sensing, Taylor and Francis publication, second edition.

- Daniels R.J.R., (1989), A Conservation Strategy for the Birds of Uttara Kannada district, Ph.D thesis, Centre for Ecological Sciences, Indian Institute of Science, Bangalore, pg.: 27.47.

- Daniels, R.J.R. 2003. Biodiversity of the Western Ghats: An overview . In ENVIS Bulletin: Wildlife and Protected Areas, Conservation of Rainforests in India, A.K. Gupta, Ajith Kumar and V Ramakantha (editors), Vol. 4, No. 1, 25-40. 
- Gururaja, K.V. 2004. Sahyadri Mandooka, http://wgbis.ces.iisc.ernet.in/biodiversity/ newsletter/issue6/index.htm

- Menon S. and Bawa K.S., (1997), Applications of Geographic information systems, Remote Sensing, and Landscape ecology approach to biodiversity conservation in the Western Ghats, Current Science, July 25 1997, Vol. 73, pg.: 134-146.

- Pascal J.P (1988), Wet Evergreen Forests of Western Ghats of India- Ecology, Structure, floristic composition and Succession, French Institute, Pondicherry.

- Pascal J.P. (1986), Explanatory booklet on the forest map of South India, French Institute, Pondicherry, Chapter-3, pg.: 19-30.

- Prasad S.N., (1998), Conservation planning for the Western Ghats of Keralo: Assessment of habitat loss and degradation, Current Science, August 10, 1998, Vol, 75, pg.: 228-235.

- Prasad S.N., Vijayan L., Balachandran S., Ramachandran V.S., and Verghese C.P.A., (1998), Conservation planning for the Western Ghats of Kerala: A GIS approach for locotion of biodiversity hot spots, Current Science, August 10 1998, Vol. 75, pg.: 211-219.

- Sreekantha, Subash Chandran M.D., Mesta D.K., Rao G.R., Gururaja K.V. and Ramachandra T.V. (2007) Fish diversity in relation to landscape and vegetation in central western ghats, India, Current Science (In Press)

- Subash Chandran M.D., (1993), Vegetation Changes in the Evergreen belt of Uttara Kannada district of Karanataka State, Ph.D thesis, Karnataka University, Dhanwad, pg.: 104-209.

- Udaya Lakshmi V., Murthy M.S.R. and Dutt C.B.S., (1998), Efficient forest resources management through GIS and remote sensing, Current Science, August 10, 1998, Vol. 75, pg.: 272-281. 